\title{
Beaching angles and evolution of stack geometry for thickened tailings - a review
}

\author{
P. Simms Carleton University, Canada \\ M.P.A. Williams ATC Williams Pty Ltd, Australia
}

T.G. Fitton ATC Williams Pty Ltd, Australia

G. McPhail Metago Environmental Engineers (Australia) Pty Ltd, Australia

\begin{abstract}
The reliable prediction or management of beach slope and stack geometry is integral to realisation of the potential benefits of thickened tailings technology. Stack geometry not only controls the storage capacity for a given footprint, but also strongly influences post-deposition geotechnical and geoenvironmental performance. Unfortunately, accurate prediction in design has proved difficult. However, there has been significant improvement in understanding the behaviour of tailings after they exit the pipe, and a number of methods for beach slope prediction have been proposed and developed. This paper reviews a selection of these methods, and examines their applicability to different deposition scenarios. Some recommendations are made to assist engineers and operators to achieve a given stack geometry.
\end{abstract}

\section{Introduction}

The reliability of beach slope prediction and control of stack evolution in thickened tailings deposits remain challenges that affect the credibility of thickened tailings technology. The overall slope angle is critical to stack design and estimation of storage capacity of a given impoundment. Too gentle a slope will enlarge impoundment footprints or require dam raises, whereas too steep a slope promotes erosion and decreases the geotechnical stability of the stack. Aspects of stack geometry that may influence engineering performance other than the equilibrium beach slope include: i) the evolving stack angle, ii) run out (the length of the beach) and, iii) individual layer thicknesses (where deposition is cycled between a number of points). All these parameters strongly influence the geotechnical and geoenvironmental performance of the stack. In central deposition, the evolving slope angle influences runoff and lateral subsurface drainage, which contribute to desiccation. For cyclic deposition, the thickness of individual layers controls the rate of desiccation, and this thickness is determined by the flow rate and rheology of the tailings as they flow down the beach. Desiccation contributes to strength but excess desiccation is a concern in sulphidic tailings due to the possibility of oxidation and acid rock drainage (ARD) generation (Fisseha et al., 2010).

While the behaviour of thickened or paste tailings in the pipeline has been studied to a significant degree (Pullum et al., 2006; Sofra, 2006; Nguyen and Boger, 1998), deposition geometry has received less attention. Many studies have focused on characterising thickened tailings geometry using a single angle (Kwak et al., 2005; Sofra and Boger, 2002) measured at the laboratory scale. However, it is observed that the average slope of deposits in the field are typically substantially less than slopes measured in the laboratory (Oxenford and Lord, 2006; Engman et al., 2004). This was partially thought to be attributed to shear thinning occurring during transport (for example, Houman et al., 2007). However, field observations have shown that the behaviour of thickened tailings deposits is dependent on scale. Smaller or younger deposits are often characterised by relatively uniform spreading flow and convex beach slope profiles, while in older or larger stacks tailings will flow in narrow channels and the beach slope profile may be concave (Williams and Meynink, 1986). Based on non-Newtonian flow theory that had been previously applied to mud and lava flows (Liu and Mei, 1989), Simms (2007) proposed that even deposits in the "spreading" stage are not characterised by a unique slope, and that the overall slope of the deposit is a function the size of the flow. Therefore, an average value of slope measured in flume tests cannot be directly extrapolated to the field. Henriquez and Simms (2009) verified the applicability of lubrication theory to describe thickened tailings 
flows for gold tailings in the laboratory, and observed the scale-dependency of the overall deposition angle of a single layer deposits. Fourie and Gawu (2010) applied equations derived from a geotechnical perspective and also noted the same scale dependency. Fourie and Gawu (2010) also investigated errors induced by sidewall friction in flume tests.

For prediction of the equilibrium beach profile for stacks where channel flow dominates, some researchers have used the concept of equilibrium between erosion and sedimentary deposition (Fitton et al., 2008; Pirouz and Williams, 2007). Others have pursued an approach based upon dissipation of kinetic energy of the tailings stream as it travels down the slope of the stack (McPhail, 1995, 2008). The variety of theories probably reflects different possible states of the tailings as they flow: laminar or turbulent, supercritical or subcritical, spreading or channelised flow. Equally, it reflects fundamental differences in approach by various researchers. For example, tailings may be observed to exit the pipe as a supercritical flow, which undergoes a hydraulic jump close to the deposition point, and subsequently converts into a spreading subcritical flow. On the same stack but later in the deposition process, the flow does not undergo a hydraulic jump, and rather forms a narrow channel, only spreading out near the bottom of the stack (Figure 1).

(a)

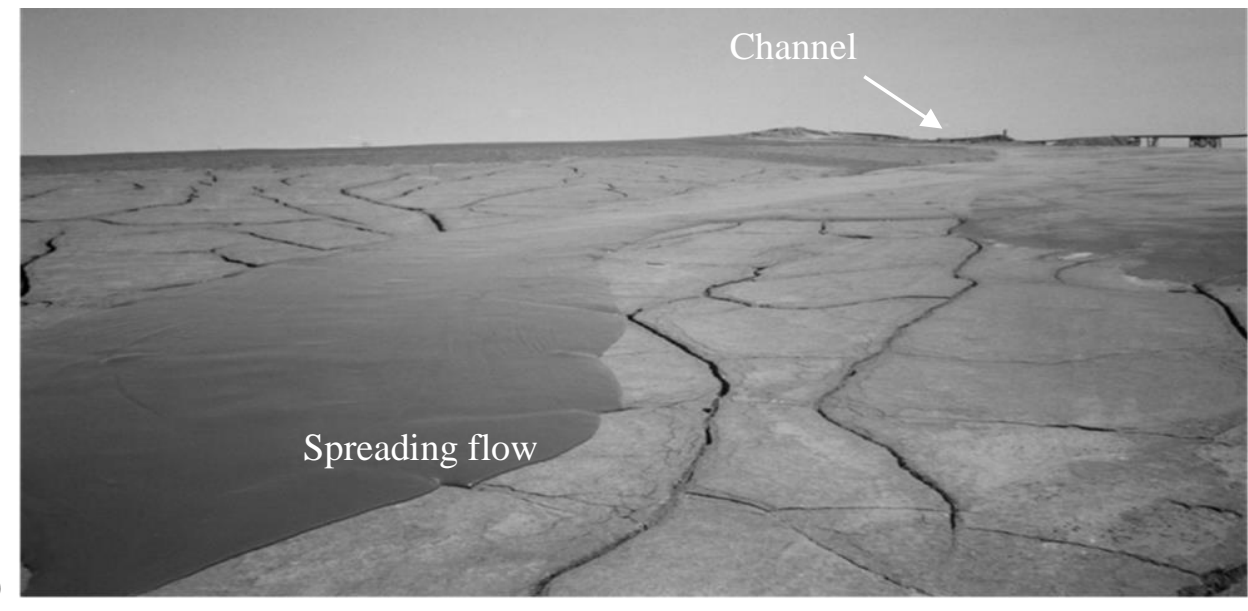

(b)

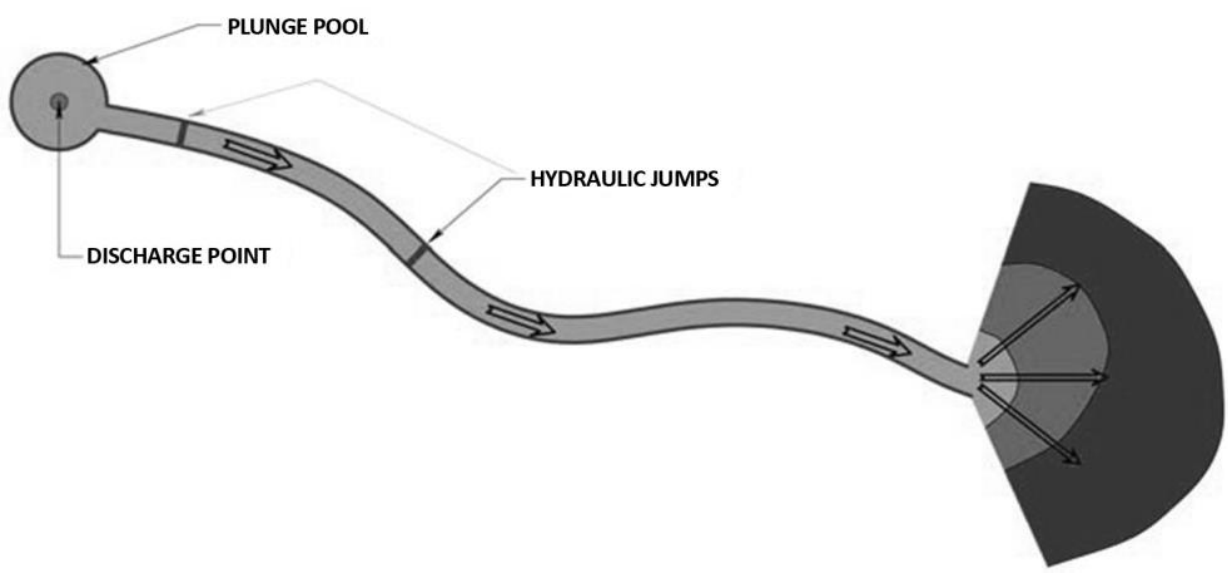

Figure 1 Photograph and schematic of initial channel flow at the deposition point, subsequently changing to spreading flow down slope (schematic by M.P.A. Williams, written comm., 2010)

This paper presents in some detail three predictive methods that have shown at least partial success in predicting or modelling field data. The methods are compared, and their relative applicability to different deposition strategies is discussed. The paper concludes with recommendations to practitioners concerning deposition strategies to regulate stack geometry.

Figure 2 is presented to give a sense to the reader of the important parameters and phenomena that can affect stack evolution and beach slope prediction. The reader will see that each predictive method accounts for some of these behaviours more than others. For example, lubrication theory considers that flows are 
dominated by viscous forces and gravity, and inertia is ignored, while in other methods inertia or stream power is of prominent consideration.

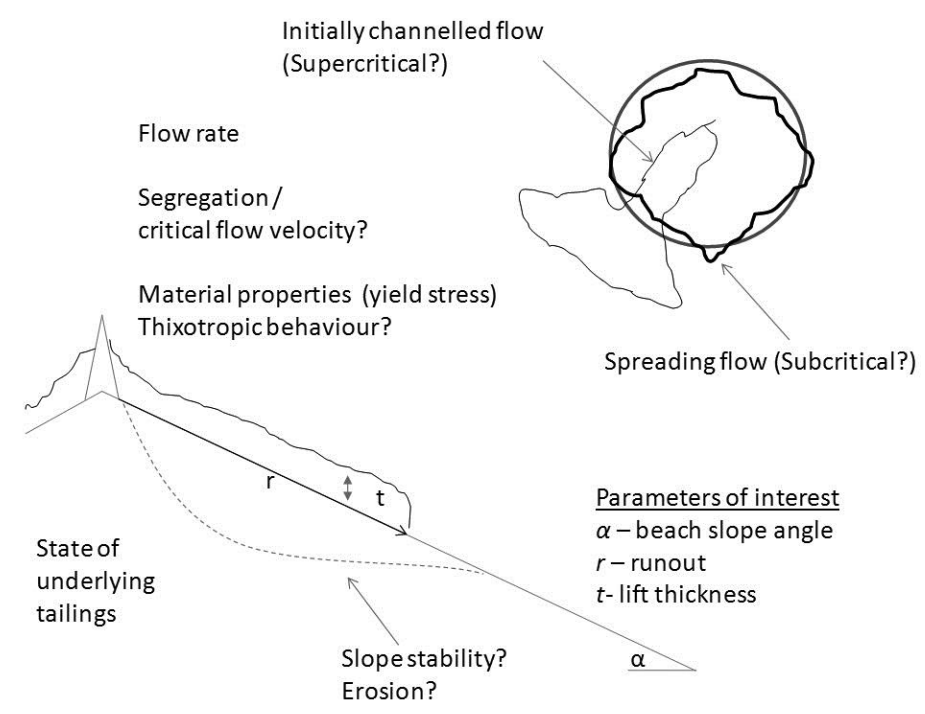

Figure 2 Tailings and deposition properties and relevant phenomena pertinent to control of stack geometry

\section{Method 1 - Fitton beach slope method}

The following model has been largely developed by Tim Fitton (Fitton et al., 2006, 2007, 2008; Fitton, 2007). The model integrates non-Newtonian open channel flow and sediment transport. It is assumed that the maximum beach slope corresponds to the slope of a channelised tailings flow, in which the tendency for erosion and sedimentation reaches equilibrium. This equilibrium is characterised by the minimum transport velocity for the tailings, which can be determined experimentally, or using the following equations.

For segregating slurry, the Wasp et al. (1977) equation is recommended:

$$
V_{c}=3.8 C_{v}{ }^{1 / 4}\left(\frac{d}{4 R_{H}}\right)^{1 / 6}\left(\frac{8 g R_{H}\left(\rho_{s}-\rho_{l}\right)}{\rho_{l}}\right)^{1 / 2}
$$

where $C_{v}$ is the solids concentration by volume fraction, $d$ is median particle diameter, $R_{H}$ is the hydraulic radius of the naturally forming channel, with the densities referring to solid particle density and density of the carrier fluid. Through observation of natural channels and sensitivity analysis of this model to channel shape, Fitton (2007) determined that predictions were generally insensitive to channel shape, and rather the aspect ratio between width and depth was the important parameter. Fitton (2007) recommends using a parabolic cross-section with a width to depth ratio of 5.5 for calculation of hydraulic radius.

For non-segregating slurries, Fitton (2007) proposed the following equation, based on experimental correlations of the critical velocity and the Reynolds number for a Bingham plastic observed in flow-through flume tests:

$$
V_{c \text { Non-seggregating }}=0.145 \ln \left(\frac{p V R_{H}}{\mu_{B P}}\right)
$$

Where the term in brackets is the Reynolds's number for a Bingham plastic, $\rho$ is bulk density of the slurry, $\mu_{B P}$ is the Bingham viscosity.

Based upon the assumed channel geometry, the slope may be determined using the following steps:

1. Assume a depth of channel, $d$.

2. Calculate $V=Q / A$, where the channel is assumed to be a parabola with width $=5.5 \mathrm{~d}$.

3. Calculate $R_{H}$, and then compute $V_{c}$ using Equations (1) or (2). Repeat Steps 1 and 2 until $V=V_{c}$.

4. Determine $R e$, using the definition of $R e$ for a Herschel-Bulkley fluid. 


$$
R e_{H B}=\frac{8 \rho V^{2}}{\tau_{y}+K\left(\frac{2 V}{R_{H}}\right)^{\eta}}
$$

The denominator of the equation is the Herschel-Bulkley equation for a flow curve, $\tau_{y}, K$ and $n$ are fitting parameters.

5. $R e$ is then used to calculate the friction factor, $f$, using the Colebrook-White Equation:

$$
\frac{1}{\sqrt{f}}=-2 \log \left[\frac{k_{S}}{14.8 R_{H}}+\frac{2.51}{R e \sqrt{f}}\right]
$$

In which $k_{s}$ is $2 D_{90}$.

6. The slope for uniform flow in the channel is calculated:

$$
S_{0}=f V^{2} /(8 g R H)
$$

$S_{0}$ is taken to be the beach slope.

\subsection{Comparisons with field observations and experiments}

The method was compared to a set of experiments conducted in a $10 \mathrm{~m}$ long flow-through flume, as well as an independent set of field data from ATC Williams. Details of the tailings used in the experiments are given in Table 1. The predictions of the method are compared to both experimental and field data in Figure 3.

Fit Plot - Fitton beach slope model

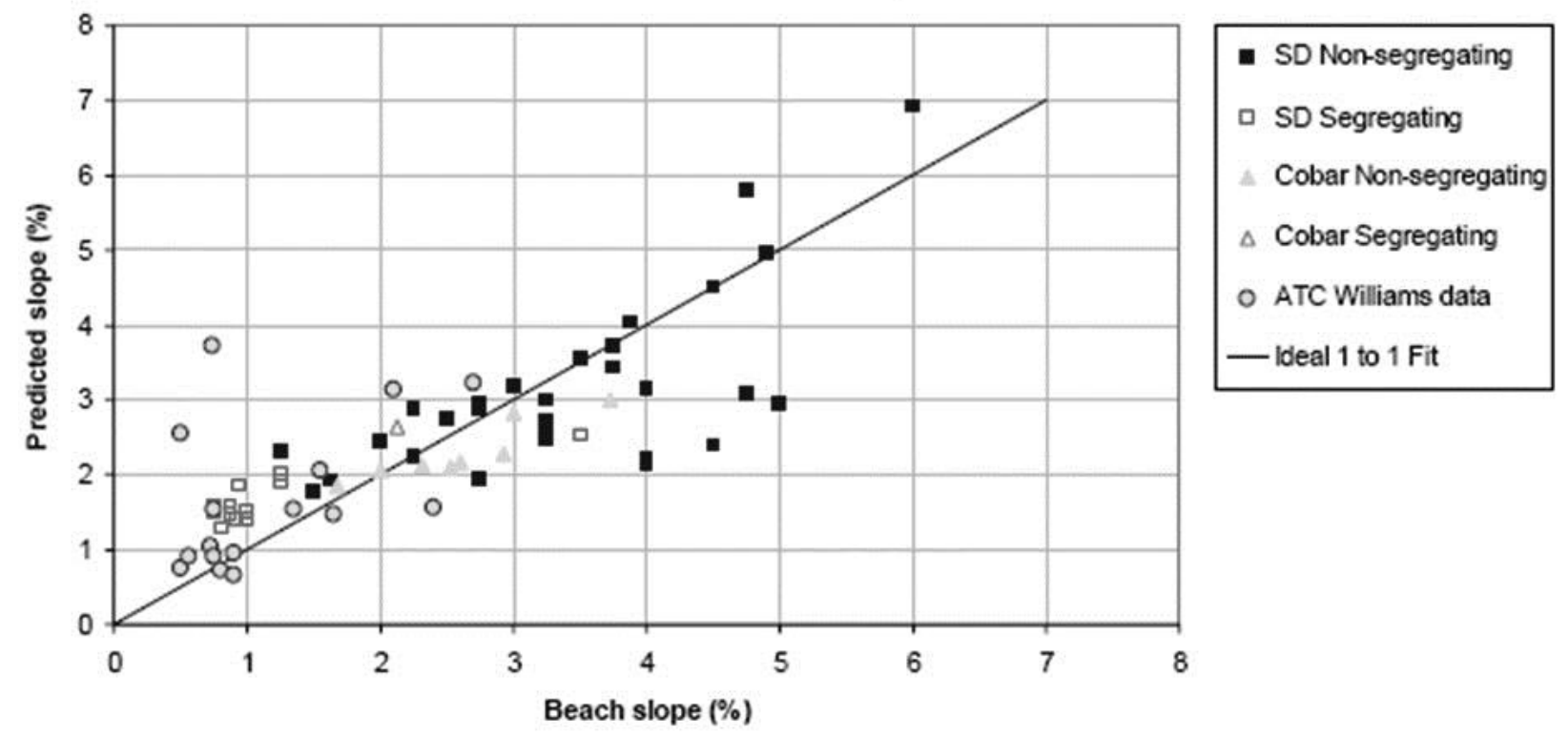

Figure 3 Fitton model applied to data from large flume test and select field data (from Fitton, 2007) 
Table 1 Tailings used to generate some of the experimental points presented in Figure 3

\begin{tabular}{lcc}
\hline Experimental Measurement & Cobar & Sunrise Dam \\
\hline No. of equilibrium slopes recorded & 9 & 41 \\
Steepest equilibrium slope (\%) & 3.7 & 6.0 \\
Flattest equilibrium slope (\%) & 1.7 & 0.75 \\
Maximum flow rate (1/s) & 19 & 24 \\
Minimum flow rate (1/s) & 1.9 & 1.9 \\
Maximum concentration (\% w/w) & 57.7 & 66.8 \\
Minimum concentration $(\%$ w/w) & 45.8 & 25.8 \\
Segregation threshold $(\%$ w/w) & $\sim 46$ & $\sim 52$ \\
\hline Herschel-Bulkley rheological fit for slurry at maximum & \\
concentration & & \\
\hline \multicolumn{1}{r}{ Yield strength, $\tau_{y}(\mathrm{~Pa})$} & 3.65 & 21.2 \\
$\quad$ Consistency index, $K(\mathrm{~Pa} . \mathrm{s})$ & 0.076 & 0.44 \\
$\quad$ Power, $n$ & 0.81 & 0.60 \\
Bingham plastic viscosity, $K_{B P}($ Pa.s $)$ & 0.016 & 0.030 \\
\hline
\end{tabular}

\section{Method 2 - McPhail stream power method}

This method was initially proposed by McPhail (1995) for conventional tailings and subsequently adapted to high density tailings (McPhail, 2008). The basic premise of the method is that beach slope profile is related to the dissipation of energy of the tailings as they move downslope in a channel. The energy is quantified as "Stream Power" in this method:

$$
P=\rho g Q H
$$

In which $H$ is the energy head and $Q$ is the discharge. Pressure head is assumed to be small, and therefore, with respect to the datum of the tailings beach, Stream Power can be expressed in terms of velocity head:

$$
P_{x}=\rho Q g\left(\frac{v_{x}^{2}}{2 g}\right)=\rho Q \frac{v_{x}^{2}}{2}
$$

On a tailings beach, velocity head falls to zero at the toe. An infinite number of stream power functions may satisfy this criteria: McPhail (1995) derived a specific equation based on maximum information entropy technique, essentially a theory that states that the likeliest model for reality, is an equation in which its sensitivity to variable uncertainty is the highest possible. More details are given in McPhail (1995). The equation produced is:

$$
P(x)=-\frac{1}{\beta} \ln \left[\left(1-\exp ^{-\beta P_{0}}\right) \frac{x}{L}+\exp ^{-\beta P_{0}}\right]
$$

The parameter $P_{0}$ is the stream power at the start of the beach (at $\left.x=0\right) . L$ is the distance from the start of the beach to the toe. The parameter $\beta$ is a constant emerging from the mathematical derivation of Equation (8). The slope at the start of the beach is obtained by differentiating Equation (8) with respect to $x$ to obtain $S_{0}$ which yields the following equation:

$$
S_{0}=-\frac{\left(1-\exp ^{-\beta P_{0}}\right)}{L \beta \exp ^{-\beta P_{0}}}
$$


The slope of the stream power curve, $S_{B}(x)$ and hence of the beach can be determined at any point, $x$, along the beach from the equation:

$$
S_{B}(x)=-\frac{\left(1-\exp ^{-\beta P_{0}}\right)}{L \beta \exp ^{-\beta P(x)}}
$$

The elevation, $y$, of the beach at any point, $x$, along the beach can be determined using the following equation and working in small increments of $\Delta x$ from the start of the beach:

$$
y=y(x+\Delta x)+S_{B}(x) \Delta x
$$

Equation (11) gives the beach profile.

The application of these equations requires the determination of i) the initial stream power of the tailings on the beach OR the height of the deposit OR the length of the deposit, and ii) the initial slope. McPhail (1995) noted that the initial stream power is not the stream power of the tailings in the pipeline. The tailings will plunge from the pipe outlet, potentially undergoing a hydraulic jump to subcritical flow, and also potentially transforming back to supercritical flow in the formation of a channel. The energy dissipation in the plunge pool may be calculated using the continuity equation in conjunction with the force-momentum flux equation and an assumption that the channel exiting the plunge pool will be semi-circular, the minimum flow section (McPhail, 1995). However, calculating a profile for a given height of deposit where the length is unknown, or for a given length where the height is unknown, is a simpler calculation.

Small-scale beaching simulations can be used to estimate a realistic flow curve for segregating slurries. This information is then used to estimate the initial beach slope for full-scale predictions.

The application of this method to prediction of full-scale beaches may be accomplished by the following steps:

1. Perform beaching simulations at the anticipated range of slurry densities at a small scale. McPhail (2008) recommended depositing tailings in the corner of a paddock at least $8 \times 8 \mathrm{~m}$ to minimise wall effects. Fit the resulting beach profiles using Equation (8) to obtain $\beta, P_{0}$, and $S_{0}$.

2. Calculate velocity down the beach from Stream Power for known density and flow rate using Equation (7).

3. Construct a shear stress - shear rate relationship down the beach, for each slurry density, using the following equations. For shear rate:

$$
\omega=2 v / R_{H}
$$

where $R_{H}$ is the hydraulic radius of the flow stream at the lip of the plunge pool, and $v$ is the mean velocity calculated in Step 2. The shape of the flow channel is assumed to be semi-circular. Channel hydraulic radius follows from continuity for known $Q$ (given) and $v$ (from Step 2).

The shear stress down the beach can be calculated using the following equation (Wasp et al., 1977):

$$
\tau=f_{f} \rho v^{2} / 2
$$

where $f_{f}$ is the Fanning friction coefficient (1/4 value of Darcy-Weisbach friction coefficient).

4. Use the full scale discharge data of slurry density, flow rate, pipe diameter, and residual pressure together with standard hydraulic calculations for the plunge pool to estimate the initial stream power for a given slurry density and flow rate for the field $\left(P_{0 f}\right)$.

5. Calculate the initial velocity exiting the plunge pool using Equation (7) from $P_{\text {of. }}$

6. Calculate the initial slope using:

$$
S_{0}=\tau / \rho g R_{H}
$$


7. For a given length $L$, the field beach slope profile can then be estimated by defining $\beta$ using Equation (9), and subsequently using Equations (8), (10), and (11) to plot the profile from the plunge pool to the supernatant pond. Shear stresses and shear rates may be calculated down the beach using the energy equation for open channel flow. If this generated rheogram does not match the actual rheogram, another value of $L$ must be chosen. In this way these calculations are iterated with $L$ until convergence between the generated and actual rheograms is achieved. Alternatively, $L$ may be fixed and calculations may be iterated with the height of the deposit.

\subsection{Comparisons with field and experimental data}

One case from McPhail (2008) is presented. This case study entails a slurry of solids SG 3.6, a maximum particle size of $1.18 \mathrm{~mm}$ and a percentage passing $0.075 \mathrm{~mm}$ of $50 \%$. The slurry was generated by hard rock mining.

Flume tests were carried out in a flume constructed directly adjacent to a pipe loop. At the end of a pipe loop test of a slurry at a particular density a portion of the flow stream was diverted to the flume. The flume measured $7 \mathrm{~m}$ long by $0.5 \mathrm{~m}$ wide. Discharge was through a $25 \mathrm{~mm}$ pipe at a flow rate of $0.8 \mathrm{l} / \mathrm{s} \mathrm{such}$ that the pipe was parallel to the beach and close to the beach elevation. The pipe was slowly raised as the beach built up. Figure 4 shows the measured beach profiles in the flume tests. Also indicated are fitted profiles based on the stream power equations described above.
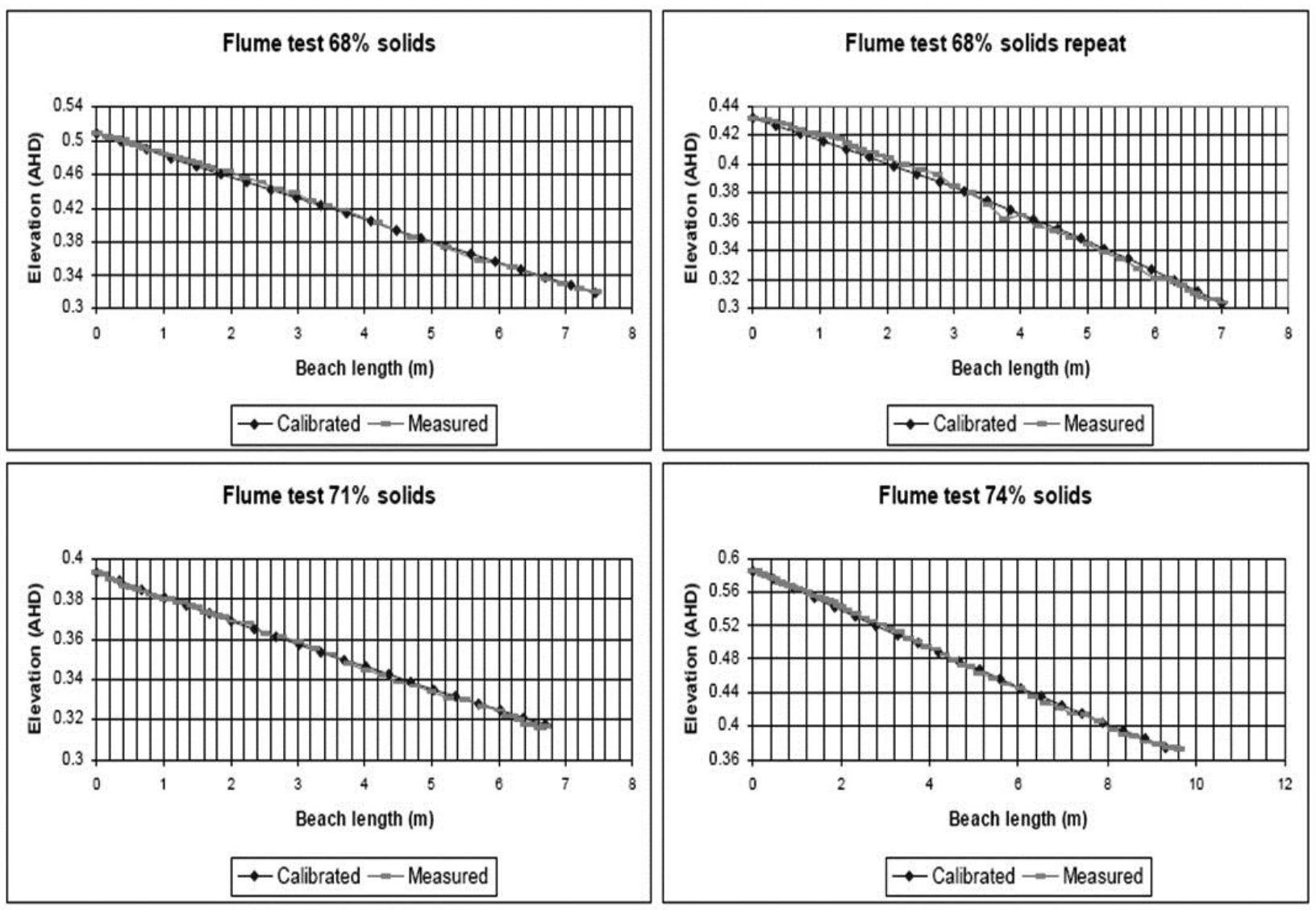

Figure 4 Measured and fitted beach profiles for the flume tests

Figure 5 shows measured beach profiles from the full scale field operations. These have been measured over the period from 2000-2004 and cover the pre-high density operations and three trial depositions all carried out in the course of routine operations as modifications to the thickening equipment were progressively implemented. Also indicated are the fitted profiles using the entropy-based stream power methodology as well as the calibrated stream power, shear rate, shear stress and fitted initial beach slope. It can be seen that the shape of the profiles are very well modelled by the method. 

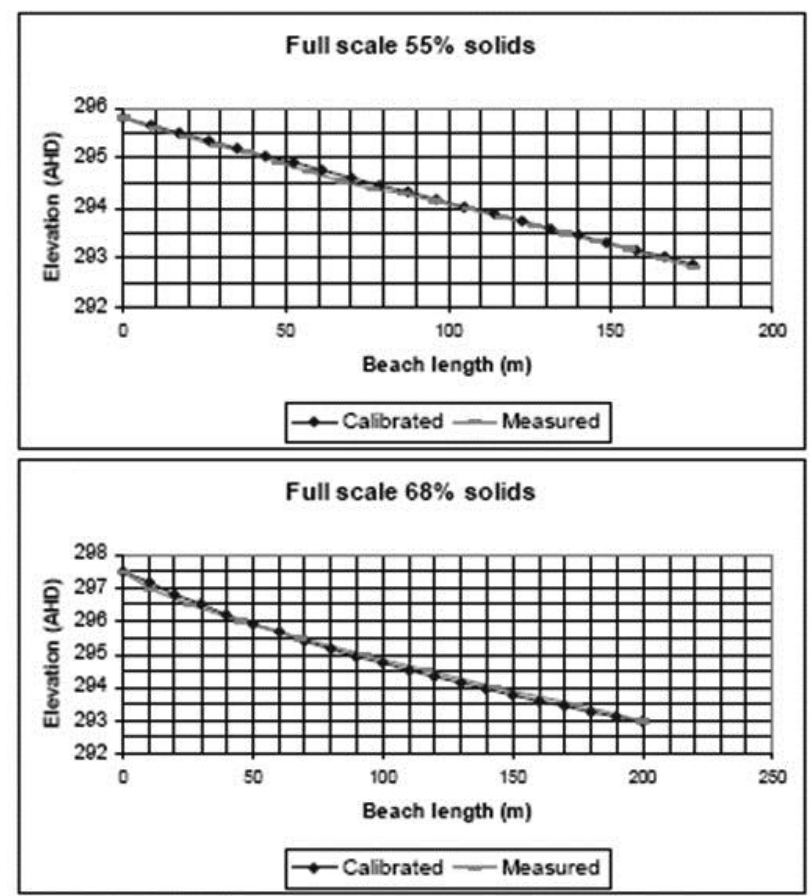

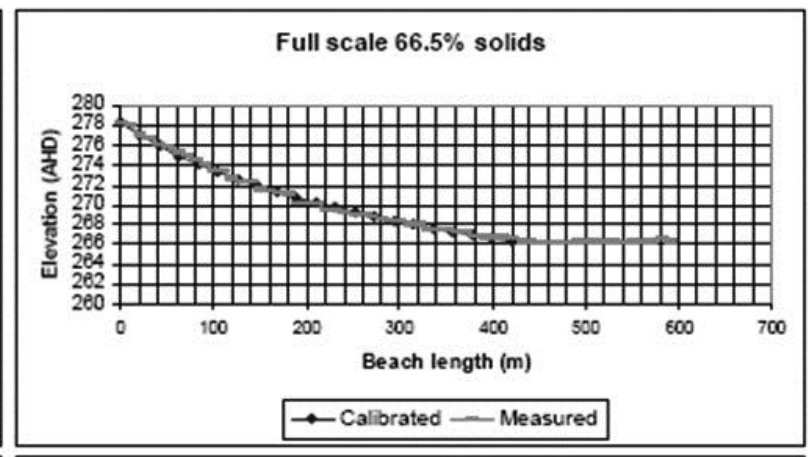

Full scale $74 \%$ solids

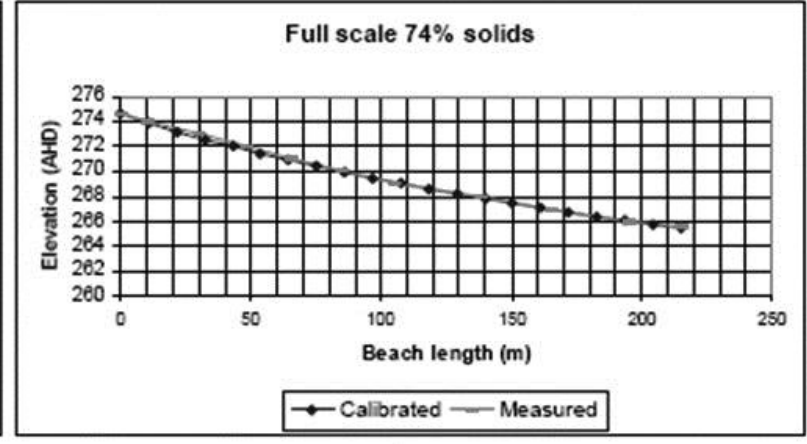

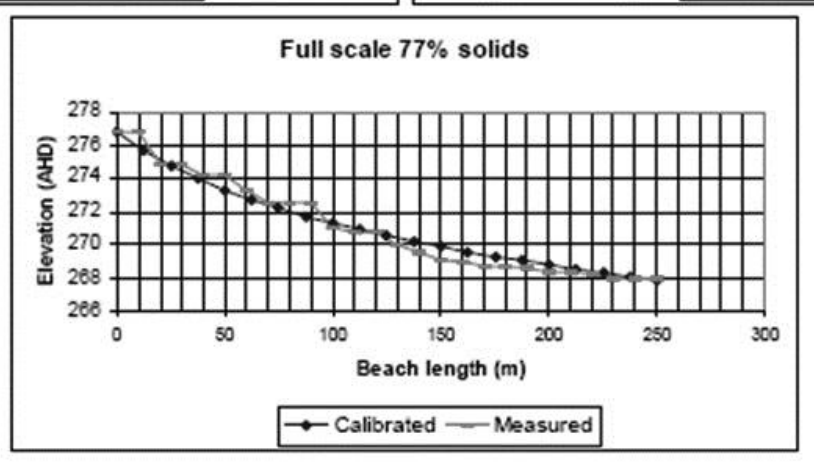

Figure 5 Measured and fitted field beach slope profiles

\section{$4 \quad$ Method 3 - Lubrication theory equations}

Lubrication theory (LT) allows for reduction of the Navier-Stokes Equations to relatively simple equations for equilibrium profiles of simple geometries for non-Newtonian fluids. The reduction is afforded by assuming:

1. Flows have a small aspect ratio (thickness/length ratio is small).

2. The ratio of inertial forces to gravitational and viscous forces are small. Therefore, LT theories are valid for a non-Newtonian fluid that spreads under its own weight, but the flow rate out of the pipe does not enter the equations.

These simplified momentum and continuity equations have been solved analytically for yield stress fluids under special geometries and special conditions by several researchers, for applications such as mud or lava flow (Yuhi and Mei, 2004; Liu and Mei, 1989; Balmforth et al., 2002; Coussot and Proust, 1996). Considering that on an inclined bed the flow is not driven by any external pressure, but rather by the volume body force of gravity, then the momentum equation in the direction of the flow is as below (Liu and Mei, 1989):

$$
\rho g \sin \theta-\frac{\partial p}{\partial x}+\frac{\partial \tau}{\partial z}=0
$$


where $p$ is pressure, $\rho$ is density, $h$ is the angle of the inclined surface from the horizontal, $g$ is the acceleration due to gravity, $\tau$ is the shear stress, the $\mathrm{x}$-axis is the direction of the inclined plane, and the $\mathrm{z}$-axis is perpendicular to the inclined plane. If one further assumes the pressure distribution to be hydrostatic, then:

$$
p=\rho g(h-z) \cos \theta
$$

Where $h$ is the depth of the free surface of the flow. Then differentiating Equation (16) to substitute it into the left-hand side of Equation (15), and solving for the shear stress, one obtains an expression in terms of depth $z$ :

$$
\tau=\rho g(h-z) \cos \theta\left(\tan \theta-\frac{\partial h}{\partial x}\right)
$$

Now, setting $z=0$, one may obtain an expression for the steady-state profile of a Bingham fluid, given the condition $\tau<\tau_{y}$, the yield stress. The equation for a flat bed is:

$$
\tau_{y}\left(x-x_{0}\right)=\frac{\rho g}{2}\left(h^{2}-h_{0}^{2}\right)
$$

where $h_{0}$ is the height at $x_{0}$. In the same vein as the derivation of Equation (18), an equation for the steadystate profile of flow from the top of an inclined hill may be derived (Yuhi and Mei, 2004):

$$
h^{\prime}-h_{0}^{\prime}+\ln \left(1-h^{\prime}\right)=x^{\prime}-x_{0}^{\prime}
$$

where $h^{\prime}$ and $x^{\prime}$ are normalised dimensionless variables, such that $h=h^{\prime}\left[\tau_{y} /(\rho g \sin \theta)\right]$ and $x=x^{\prime} \cot \theta$ $\left[\tau_{y} /(\rho g \sin \theta)\right]$.

As shown in Simms (2007), Henriquez and Simms (2009) and Mizani et al. (2010a, 2010b), these equations very well describe equilibrium flume profiles for both single and multilayer deposits at the laboratory scale ( $<3 \mathrm{~m}$ in length), for gold tailings and kaolinite; and have been fit to single layer profiles at a gold mine ( $\sim 50 \mathrm{~m}$ run out). An important aspect of these equations is they show the scale dependency of the overall angle of single layer flows (Figure 6). Therefore, the overall angle observed in flume tests cannot be directly extrapolated to the field. In the following figures, Equation (18) is used to model the first layer, whereas Equation (19) is used to fit all subsequent layers, using the average angle for the previous layer. In all the tests shown, each layer was left for 24 hours before the next layer was placed. This generally coincided with the end of settling but before desiccation and generation of negative pore-water pressures. Figure 7 shows the fit to a 3D small scale simulation of stacking: for each layer, the same density and yield stress $\left(1,900 \mathrm{~kg} / \mathrm{m}^{3}\right.$ and $30 \mathrm{~Pa}$ ) are used.

The LT theory works well up to a point. As illustrated in Figure 8, once a deposit reaches a certain slope, there is a change in flow regime and the tailings begin to flow in channels from the deposition point some distance down the slope. This is coincident with the beginning of concavity in the beach slope profile, and failure of the LT equations.

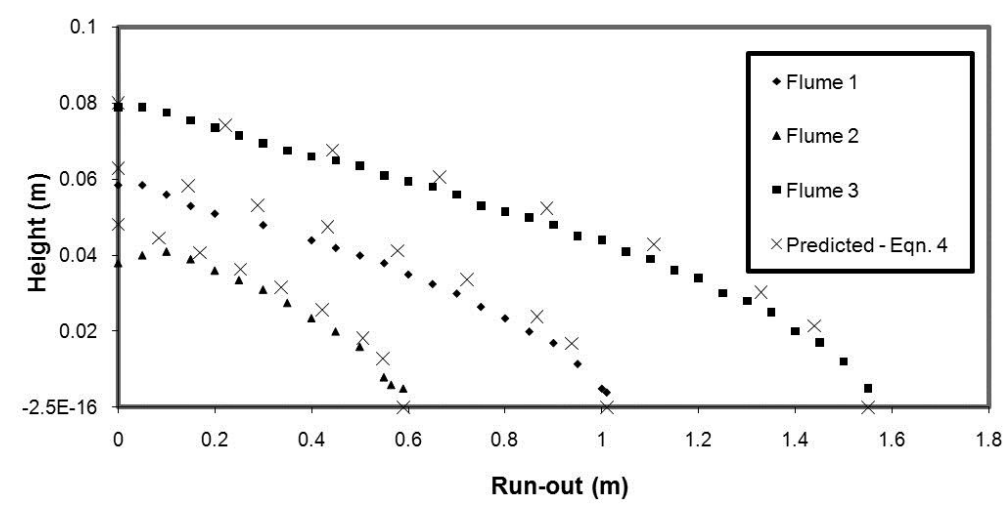

Figure 6 Three single layer flows of different volume, each fit with Equation (18) using the same material parameters (density and yield stress) 


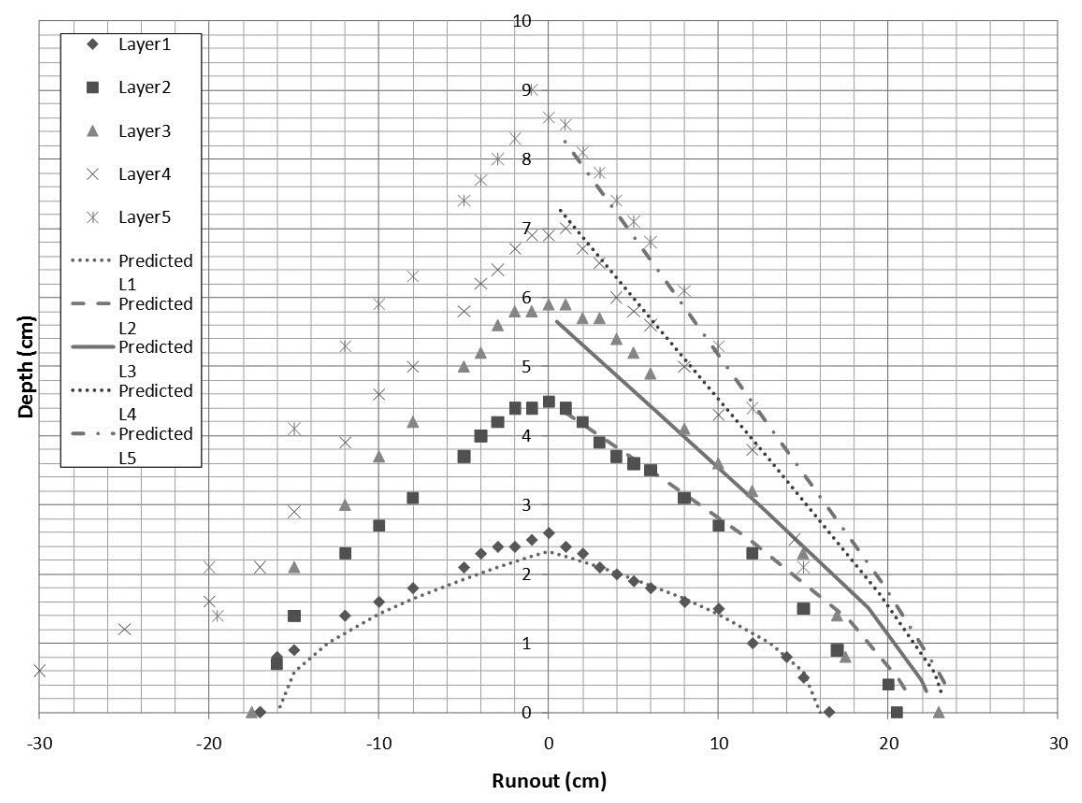

Figure 7 Early deposition in a small-scale 3D simulation, $Q=0.4$ LPM, 2.6 L per layer; yield stress $30 \mathrm{~Pa}$; density $1,900 \mathrm{~kg} / \mathrm{m}^{3}$

(a)

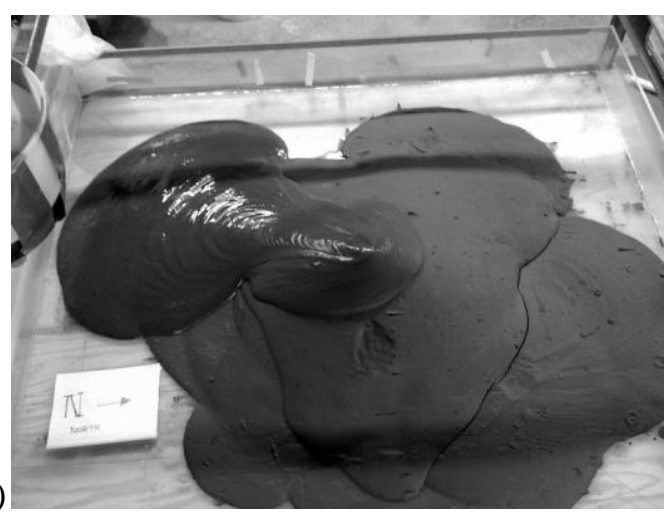

(b)
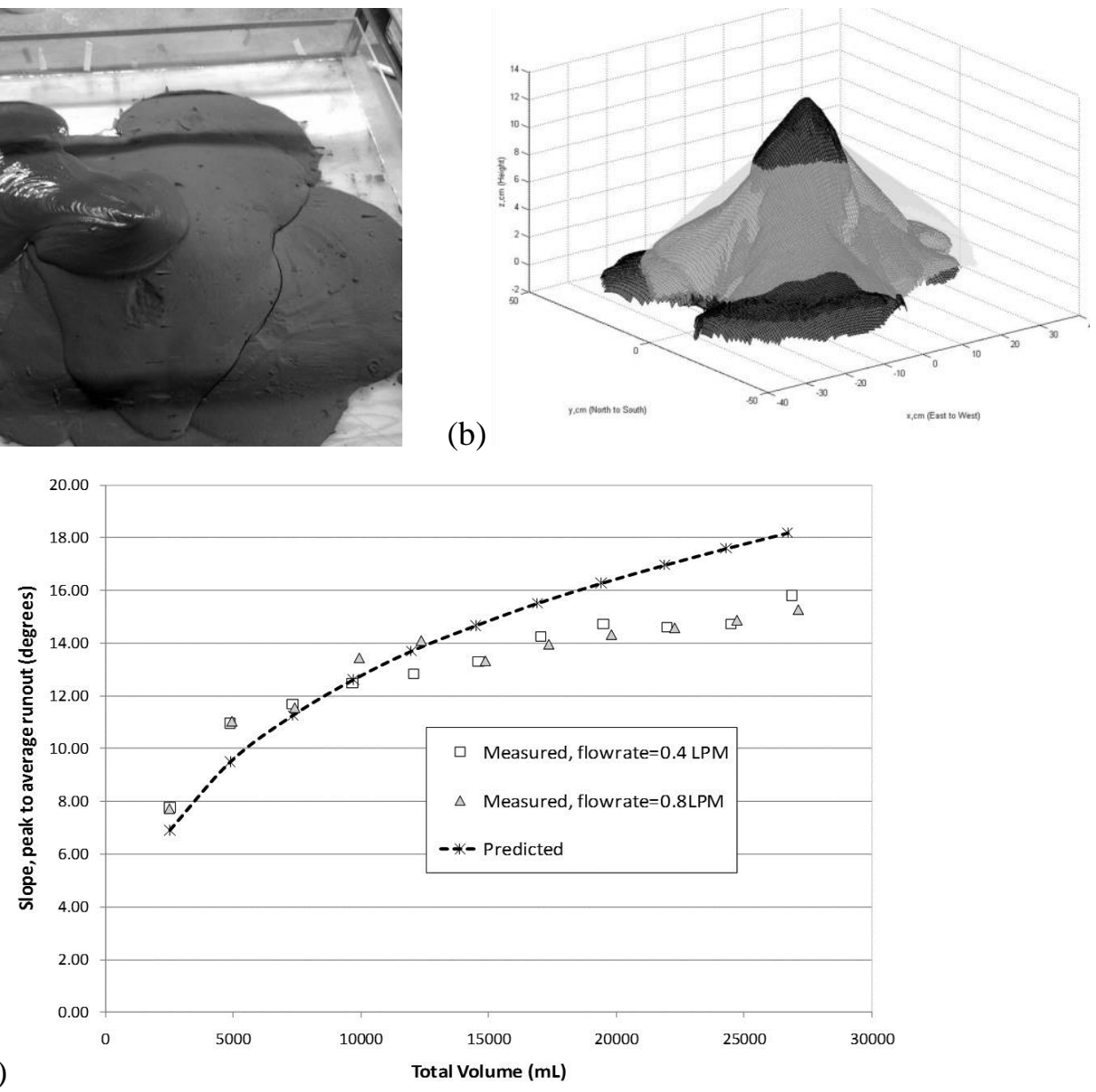

Figure 8 Change in flow regime from 'spreading' to channelised flow, coincident with increasing concavity of slope profile. Each point denotes a layer, $2.6 \mathrm{~L}$ each; (a) and (b) show a deposit with 8 layers, pale cone in (b) is the predicted shape using the LT equations 


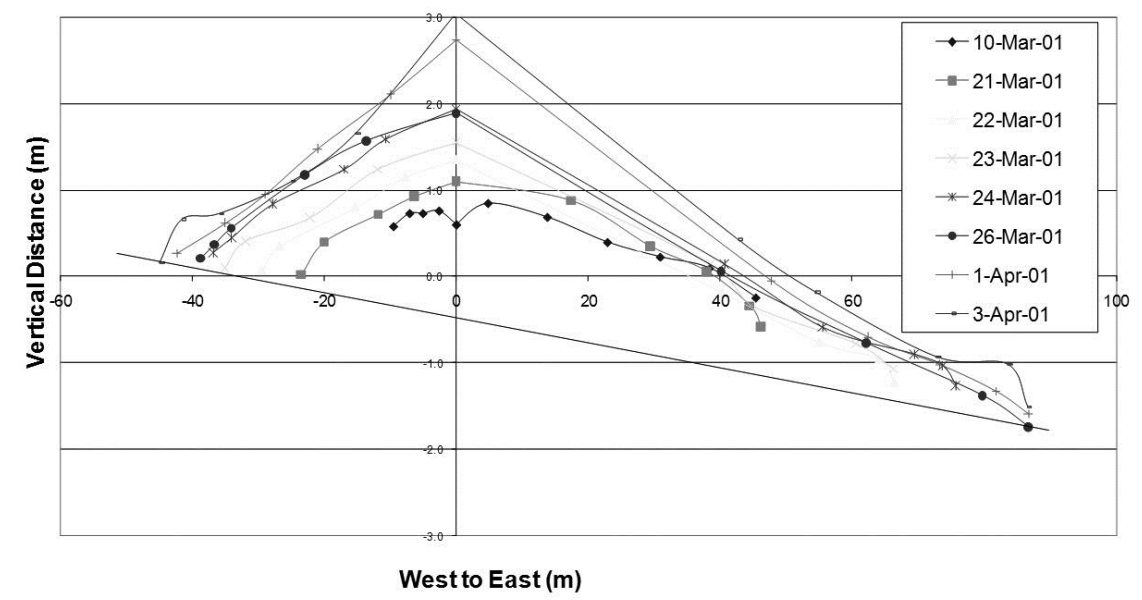

Figure 9 Early deposition at one tower at Bulyanhulu (J.J.C. Crowder, written comm., 2007)

The same trend seen in Figures 7 and 8 can be observed during early deposition at the Bulyanhulu site (Figure 9). The shape of the tailings stack evolves from a convex profile, becoming more linear and eventually concave. This progression of slope shapes is observed at other thickened tailings sites, as noted by Williams and Meynink (1986) and Fitton (2007).

It is of interest to define the slope when the flow changes from spreading to channel flow. This is not only of interest as to the limitation of the LT approach, but also tells the engineer when the flow becomes less manageable, with respect to controlling individual lift thickness. One hypothesis, as yet unproven, is that limits to the LT equations can be defined by a Froude number. One can approximately find the Froude number as a function of distance from the deposition point, $r$, assuming uniform axisymmetric flow down a uniform slope, and using Manning's equation and continuity to derive expressions for depth $d$ and mean velocity as a function of distance from the deposition point, $r$ :

$$
\begin{gathered}
d=\left(\frac{Q n}{2 \pi r S_{0}{ }^{1 / 2}}\right)^{3 / 5} \\
V=\frac{Q}{2 \pi r d}
\end{gathered}
$$

Where $n$ is Manning's coefficient for overland flow. The Froude number, $V /(g d)^{0.5}$, can then be evaluated as a function of radial distance from the deposition point.

A solution is shown in Figure 10, for $Q=0.0205$ and $n=0.06$ for two slopes. It is seen that the Froude number decreases down the beach. Thus, in order to evaluate the stability of spreading flow, a realistic minimum radius of flow must be selected. Selecting the minimum radius as the radius of the pipe seems a reasonable and probably conservative assumption, as increasing $r$ would increase the critical slope.

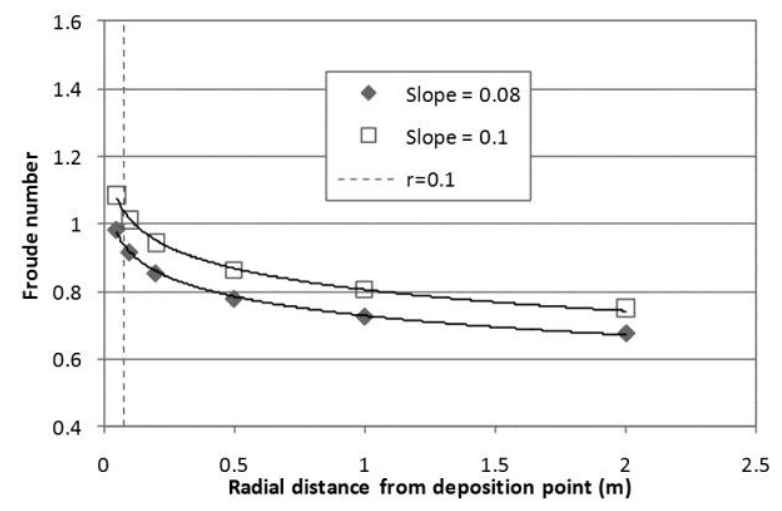

Figure 10 Simple estimate of Froude number down the beach, for initially axisymmetric spreading flow; $Q=0.0205 \mathrm{~m}^{3} / \mathrm{s}, n=0.6$ 
In this example, flow rate corresponds to that at the Bulyanhulu Mine for early deposition, such as presented in Figure 10. The Manning's coefficient was determined by applying Equations (20) and (21) to the smallscale deposition simulations in Figures 7 and 8, when the critical angle is known from Figure 8c, and the onset of channelling flow was assumed to correspond to $F r=1$. A slope of 0.10 gives a Froude number of $\sim 1$ for a pipe radius of $0.1 \mathrm{~m}$. Looking at the slope of Figure 9 with relation to the horizontal, we can approximate the slope when a concave beach slope starts to develop at the data recorded on April 1st, on the West side of the deposit. The elevation is $\sim 2.8 \mathrm{~m}$, and the run out $\sim 42 \mathrm{~m}$, gives a slope of 0.067 . This is promising but further refinement of Equations (20) and (21) is probable in the face of data from other sites.

It is important to note that even the "non-segregating" tailings may exhibit significant thixotropic behaviour while flowing (Mizani et al., 2010a, 2010b). This occurs both by natural settling and by adsorption of moisture by the underlying tailings. Thus the best-fit yield stress for the LT equations for small-flume tests may underestimate the value relevant to the field (30 Pa compared to $100 \mathrm{~Pa}$ for the Bulyanhulu tailings). Mizani et al. (2010b) recommended using slow rates of deposition in multilayer trial tests with dimensions as large as practicable to simulate the same time of deposition as would occur in the field, where the underlying tailings are left to dry significantly before placement of the next layer.

Finally, given the restriction of the LT approach to spreading flow, what is its utility? One, it can be used to estimate or model layer thickness as the stack initially builds up. Second, it can be used to model how quickly the stack will arrive at the critical angle. This is of interest to engineers who wish to control layer thickness in a cyclic deposition scheme, as beyond the onset of channelling flow control of layer thickness is more challenging. Consider Figure 11, where two alternate deposition schemes are contemplated. It can be seen that the deposition scheme with the longer cycle time, allows for more volume to be deposited at a given deposition point, before the critical angle is reached.

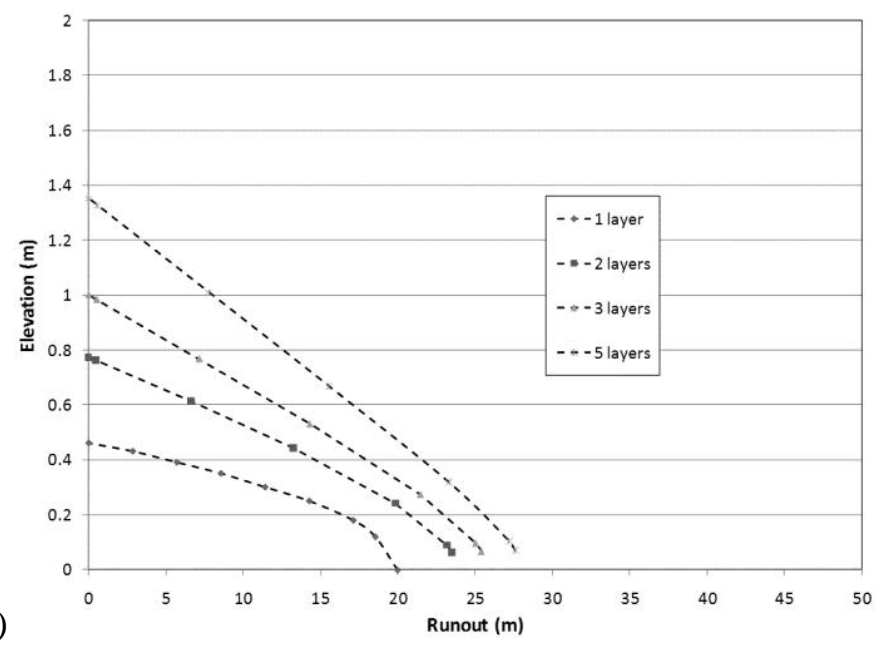

(a)

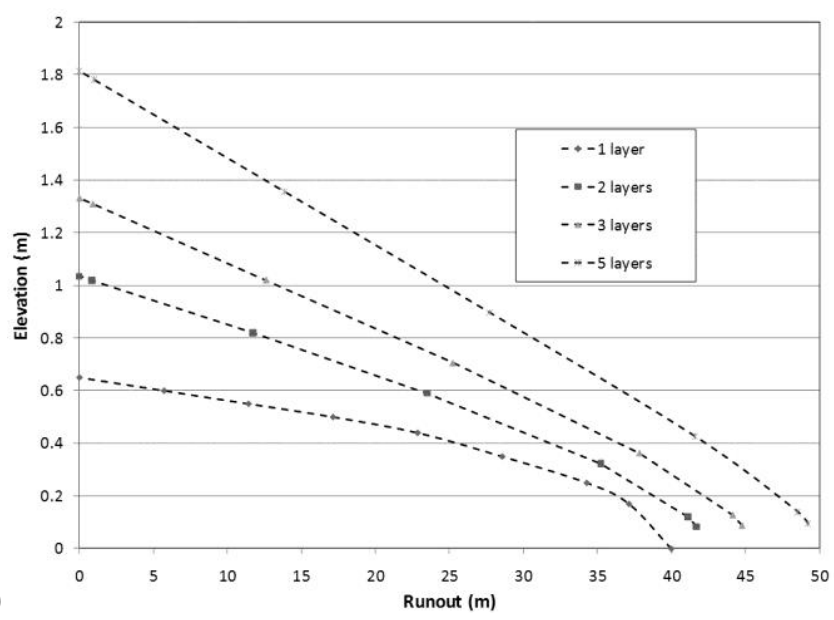

Figure 11 Improving deposition point capacity by increasing deposition volume below critical angle, using Equations (18) and (19) 


\section{Discussion - comparison of methods}

To illustrate the relationship between the different methods, they will be compared to the evolution of stack geometry at the Bulyanhulu mine. While this mine is not typical of thickened tailings deposits, due to the relatively high solids concentration of the tailings and cyclic deposition scheme, the relatively rich data set on field profiles and rheological properties that is available in the literature allows for some interesting comparisons. Early deposition (Figure 9) shows gradually increasing overall angles, which achieved a maximum slope between 1:10 and 1:14 or 10\% and 7\% (Shuttleworth et al., 2005). Later observations (Addis and Cunningham, 2010) showed the development of a highly concave profile, the beach slope ranging from $9 \%$ within $30 \mathrm{~m}$ of the deposition point, to a $3 \%$ slope fit through the peak and the toes for run outs of $\sim 300 \mathrm{~m}$. The overall slope, in terms of estimating a cone of equal volume for the footprint, was $\sim 4 \%$.

This history is interesting as it suggests that the overall slope achieved a maximum value, and that the overall slope began to decrease once a concave slope profile was established. This is of interest to mine operators in terms of maximising footprint capacity and for efficient spreading of the tailings.

Figure 12 presents a comparison of beach slopes predicted using Method 1 and Method 2 with the beach slope profile measured by Addis and Cunningham (2010). Method 3 was not used to predict any full length beach slopes due to the limitations of the method, which were discussed earlier. The data required for the methods were obtained by laboratory measured parameters presented in Kwak et al. (2005) and Henriquez and Simms (2009). A Bingham model was assumed for the tailing's rheogram, with a Bingham viscosity of $0.1 \mathrm{PaS}$ measured by Kwak et al. (2005). Two yield stresses have been used in the predictions, one value of $50 \mathrm{~Pa}$ measured by Kwak et al. (2005) and one value of $100 \mathrm{~Pa}$ shown to be a best fit to the individual layer profiles in the field (Henriquez and Simms, 2009). Mizani et al. (2010a) argued that $100 \mathrm{~Pa}$ may be more applicable to the field due to thixotropic effects manifested at the field scale. Other data used in the predictions include $\mathrm{D}_{90}\left(80\right.$ microns), slurry density $\left(1,900 \mathrm{~kg} / \mathrm{m}^{3}\right)$, and flow rate $(20.5 \mathrm{l} / \mathrm{s})$.

For Method 1, Equation (2), the critical velocity for non-settling slurry, was employed. Employing the higher yield stress gave a very good estimate of the overall slope (4\%), while employing the lower yield stress gave a slope of $2.7 \%$. For Method 2, the calculation was performed for a known length, and solutions iterated with the height of the deposit. For Method 2, the best fit with the field data was for a yield stress of $50 \mathrm{~Pa}$, with an average slope of 5\%, while employing a $100 \mathrm{~Pa}$ yield stress gave an average slope of $7 \%$.

Readers should note that as this comparison is with a single profile only, Figure 12 cannot be seen to validate either method, due to the danger of a fortuitous result. However, what is of interest is the sensitivity in the predictions to a variation in the parameters - in this case the yield stress. In both cases, an important variation in average slope (1.3\% and $2 \%)$ occurred due to the variation in yield stress. All authors stress the importance of determining the relevant field properties, especially with respect to rheology.

On the issue of concavity, the authors propose two explanations as to why non-segregating tailings should produce an equilibrium beach slope profile with curvature. Fitton (2007) ascribes concavity to variability in the properties of the tailings delivered, and has developed beach slope modelling methods using this assumption (Fitton et al., 2008). By contrast, in the method of McPhail (1995) concavity is built into the equation for stream power dissipation. Additionally, the experiments presented in the description of Method 3 show that concavity seems to arise under controlled conditions; at fixed flow rates and slurry concentrations; at a repeatable angle for a given tailings deposited at a given flow rate; and is coincident with the initiation of channel flow. One of the authors noted that concavity is seen in natural topographies where significant rain erosion occurs, indeed, soil covers are sometimes designed to mimic these natural topographies to minimise damage to the cover by rain erosion (Ayres et al., 2007). These possible explanations of concavity are not mutually exclusive.

Given the inherent uncertainty associated with the prediction of beach slopes and profiles, it is better for engineers to manage this uncertainty. All three approaches show that the average equilibrium slope is a function of flow rate, and that slower flow rates produce steeper angles. Therefore, practitioners may wish to explore the simultaneous use of multiple deposition points or spigots, to minimise tailings channel velocity and subsequent erosion. 


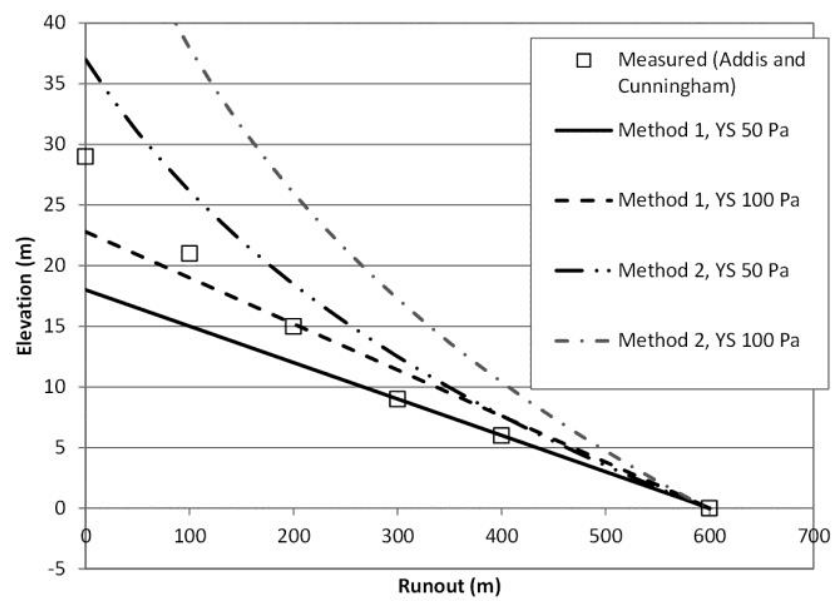

Figure 12 Predicted curves of beach slope and profile for data on Bulyanhulu from Addis and Cunningham (2010), for assumed yield stresses of 50 and $100 \mathrm{~Pa}$

\section{$6 \quad$ Summary and conclusions}

Three methods of analysis of stack slopes and stack profile prediction are examined. These methods, despite different philosophies and contexts in which they were developed, complement each other to some degree, and each may be useful to engineers to anticipate stack geometry evolution (Methods 2 and 3) and to predict thickened tailings beach slopes (Methods 1 and 2). Methods 1 and 2 are based on analysis of channelised flows that develop later in tailings deposition. Method 1 assumes the equilibrium profile is reached when erosion and sedimentation are in equilibrium, and determines this point through uniform flow calculations, assuming a parabolic channel cross-section. Method 2 is based on dissipation of energy down slope, and is implicitly a non-uniform flow analysis. Method 3 uses lubrication theory to predict equilibrium profiles of spreading flow for tailings of constant material properties.

Each method was applied to analyse the evolution of geometry at the Bulyanhulu site, a non-segregating relatively highly thickened gold tailings, which is characterised by the overall beach slope reaching a maximum value in early deposition, after which the overall slope degrades with time. It is suggested that this degradation is coincident with the initiation of a concavity in the profile. The tailings at Bulyanhulu are initially thickened by filters and then remixed with water prior to pipeline transport, and are likely to have a much more uniform consistency than tailings thickened in conventional tank thickeners.

Method 1 and Method 2 both gave reasonable estimates of the beach profile (within $1 \%$ of the measured average slope) at Bulyanhulu as measured by Addis and Cunningham (2010), for a plausible set of material parameters. However, the sensitivity of both method's predictions to the plausible range of yield stress is significant, and illustrates the importance of determining the rheological properties relevant to the field, which do not necessarily correspond to data determined using laboratory tests. All of the authors recommend various kinds of pilot-scale tests to investigate field scale behaviour, where practicable.

Method 3 may find application in estimating layer thickness and beach slope evolution of cyclic deposition schemes during the early evolution of the impoundment. A calculation based on estimating the onset of channel flow is proposed to define the upper limit of this method. This limit may also prove to be useful at operations where control of individual layer geometry is desired for purposes of regulating desiccation.

Whereas Method 1 is the most straightforward method to predict beach slope, Method 2 is the only method that directly simulates a concave profile. Some of the authors believe that concavity may be explained by variability in tailings slurry concentration delivered to the deposition point, while others believe that concavity may arise even for slurries of relatively constant concentration and rheology. These explanations are not mutually exclusive. Nevertheless, more research is required on concavity due to its importance to the applicability of the methods presented. 


\section{Acknowledgements}

The authors would like to acknowledge the various sponsors of their work on beach slope prediction: Golder PasteTec, Barrick Gold, ATC Williams, and Metago Engineering.

\section{References}

Addis, P.C. and Cunningham, E.J. (2010) Comparison of beaching slopes of thickened tailings deposits, in Proceedings 13th International Seminar on Paste and Thickened Tailings (Paste2010), R.J. Jewell and A.B. Fourie (eds), 3-6 May 2010, Toronto, Canada, Australian Centre for Geomechanics, Perth, pp. 231-240.

Ayres, B.K., Lanteigne, L., Smith, Q. and O'Kane, M. (2007) Closure Planning and Implementation at CVRD Inco's Whistle Mine, Ontario, Canada, in Proceedings Second International Seminar on Mine Closure (Mine Closure 2007), A.B. Fourie, M. Tibbett, J.V. Wiertz (eds), 16-19 October 2007, Santiago, Chile, pp. 301-312.

Balmforth, N.J., Craster, R.V. and Sassi, R. (2002) Shallow viscoplastic flow on an inclined plane, Journal of Fluid Mechanics, Vol. 470, pp. 1-29.

Cousset, P. and Proust, S. (1996) Slow, unconfined spreading of a mudflow, Journal of Geophysical Research, Vol. 101(B11), pp. 217-229.

Engman, M., Sellgren, A., Sundquist, A., Wennberg, T. and Goldkuhl, I. (2004) Users perspectives on the design of high density base metal tailings handling systems, in Proceedings 11th Tailings and Mine Waste Conference, 10-13 October 2004, Vail, USA, pp. 45-54.

Fisseha, B., Bryan, R. and Simms, P. (2010) Evaporation, Unsaturated Flow, and Salt Accumulation in Multilayer Deposits of a "Paste" Gold Tailings, Journal of Geotechnical and Geoenvironmental Engineering, Vol. 136, No. 12,1703 p.

Fitton, T.G., Bhattacharya, S.N. and Chryss, A.G. (2008) Three-dimensional modelling of tailings beach shape, Computer-aided Civil and Infrastructure Engineering, Vol. 23, pp. 31-44.

Fitton, T.G., Chryss, A.G. and Bhattacharya, S.N. (2006) Tailings beach slope prediction: A new rheological method, International Journal of Surface Mining, Reclamation and Environment, Vol. 20, No. 3, pp. 181-202.

Fitton, T.G., Seddon, K.D., Williams, M.P.A., Bhattacharya, S.N. and Chryss, A.G. (2007) Simulation of Thickened Tailings Stacks, in Proceedings Tenth International Seminar on Paste and Thickened Tailings (Paste07), A.B. Fourie and R.J. Jewell (eds), 13-15 March 2007, Perth, Australia, Australian Centre for Geomechanics, Perth, pp. 305-314.

Fitton, T.G. (2007) Tailings beach slope prediction, PhD thesis, RMIT University, Australia (Since published as a book by VDM Verlag, Saarbrucken, Germany in 2010).

Fourie, A.B. and Gawu, S.K.Y. (2010) The validity of laboratory flume data for predicting beach slopes of thickened tailings deposits, in Proceedings 13th International Seminar on Paste and Thickened Tailings (Paste2010), R.J. Jewell and A.B. Fourie (eds), 3-6 May 2010, Toronto, Canada, Australian Centre for Geomechanics, Perth, pp. 241-254.

Henriquez, J. and Simms, P. (2009) Dynamic imaging and modelling of multilayer deposition of gold paste tailings, in Minerals Engineering, Vol. 22(2), pp. 128-139.

Houman, J., Paterson, A.J.C. and van Sittert, F. (2007) Quantifying the effect of pump shear on slurry rheology, in Proceedings Tenth International Seminar on Paste and Thickened Tailings (Paste07), A.B. Fourie and R.J. Jewell (eds), 13-15 March 2007, Perth, Australia, Australian Centre for Geomechanics, Perth, pp. 163-174.

Liu, K.F. and Mei, C.C. (1989) Approximate equations for the slow spreading of a thin sheet of Bingham plastic fluid, Physics of Fluids A (Fluid Dynamics), Vol. 2(1), pp. 30-36.

Kwak, M., James, D.F. and Klein, K.A. (2005) Flow behaviour of tailings paste for surface disposal, International Journal of Mineral Processing, Vol. 77(3), pp. 139-153.

McPhail, G. (1995) Prediction of the beaching characteristics of hydraulically placed tailings, PhD Dissertation submitted to the University of the Witwatersrand, Johannesburg, South Africa.

McPhail, G. (2008) Prediction of the Beach Profile of High Density Thickened Tailings from Rheological and Small Scale Trial Deposition Data, in Proceedings 11th International Seminar on Paste and Thickened Tailings (Paste08), A.B. Fourie, R.J. Jewell, P. Slatter and A. Paterson (eds), 5-9 May 2008, Kasane, Botswana, Australian Centre for Geomechanics, Perth, pp. 179-188.

Mizani, S., He, L. and Simms, P. (2010a) "Out of Pipe" dewatering of thickened tailings during deposition, in Proceedings 13th International Seminar on Paste and Thickened Tailings (Paste2010), R.J. Jewell and A.B. Fourie (eds), 3-6 May 2010, Toronto, Canada, Australian Centre for Geomechanics, Perth, pp. 393-402.

Mizani, S., He, X. and Simms, P. (2010b) Application of lubrication theory to modeling stack geometry of thickened mine tailings, submitted to Journal of Non-Newtonian Fluid Mechanics, Oct. 2010.

Nguyen, Q.D. and Boger, D.V. (1998) Application of rheology to solving tailings disposal problems, International Journal of Mineral Processing, Vol. 54(3-4), pp. 217-233. 
Oxenford, J. and Lord, E.R. (2006) Canadian Experience in the application of paste and thickened tailings for surface disposal, in Proceedings Ninth International Seminar on Paste and Thickened Tailings (Paste06), R.J. Jewell, S. Lawson and P. Newman (eds), 3-7 April 2006, Limerick, Ireland, Australian Centre for Geomechanics, Perth, pp. 93-105.

Pirouz, B. and Williams, M.P.A. (2007) Prediction of non-segregating thickened tailings beach slopes - a new method, in Proceedings Tenth International Seminar on Paste and Thickened Tailings (Paste07), A.B. Fourie and R.J. Jewell (eds), 13-15 March 2007, Perth, Australia, Australian Centre for Geomechanics, Perth, pp. 315-327.

Pullum, L., Graham, L., Rudman, M. and Hamilton, R. (2006) High concentration suspension pumping, Minerals Engineering, Vol. 19, pp. 471-477.

Shuttleworth, J.A., Thomson, B.J. and Wates, J.A. (2005) Surface disposal at Bulyanhulu - practical lessons learned, in Proceedings Eighth International Seminar on Paste and Thickened Tailings (Paste05), R.J. Jewell and S. Barrera (eds), 20-22 April 2005, Santiago, Chile, Australian Centre for Geomechanics, Perth, pp. 207-218.

Simms, P. (2007) On the relation between laboratory flume tests and deposition angles of high density tailings, in Proceedings Tenth International Seminar on Paste and Thickened Tailings (Paste07), A.B. Fourie and R.J. Jewell (eds), 13-15 March 2007, Perth, Australia, Australian Centre for Geomechanics, Perth, pp. 329-335.

Sofra, F. (2006) Rheological assessment - a road map for plant designers and operators, in Proceedings Ninth International Seminar on Paste and Thickened Tailings (Paste06), R.J. Jewell, S. Lawson and P. Newman (eds), 3-7 April 2006, Limerick, Ireland, Australian Centre for Geomechanics, Perth, pp. 13-24.

Sofra, F. and Boger, D.V. (2002) Environmental rheology for waste minimisation in the minerals industry, Chemical Engineering Journal, Vol. 86 (3), pp. 319-330.

Wasp, E.J., Kenny, J.P. and Gandhi, R.L. (1977) Solid-liquid flow slurry pipeline transportation, Trans Tech Publications, Germany.

Williams, M.P.A. and Meynink, W.J.C. (1986) Tailings beach slopes, paper presented to Workshop on Mine Tailings Disposal, The University of Queensland.

Yuhi, M. and Mei, C.C. (2004) Slow spreading of fluid mud over a conical surface, Journal of Fluid Mechanics, Vol. 519(25), pp. 337-358. 